\title{
SRAP analysis of genetic diversity of nine native populations of wild sugarcane, Saccharum spontaneum, from Sichuan, China
}

\author{
D. Chang ${ }^{1,2 *}$, F.Y. Yang ${ }^{3 *}$, J.J. Yan ${ }^{1 *}$, Y.Q. Wu ${ }^{4}$, S.Q. Bai ${ }^{1,2}$, X.Z. Liang ${ }^{1,2}$, \\ Y.W. Zhang ${ }^{3}$ and Y.M. Gan' \\ ${ }^{1}$ Sichuan Academy of Grassland Sciences, Chengdu, Sichuan, China \\ ${ }^{2}$ Department of Grassland Science, College of Animal Science and Technology, \\ Sichuan Agricultural University, Ya'an, Sichuan, China \\ ${ }^{3}$ Grassland Institute, China Agricultural University, Beijing, China \\ ${ }^{4}$ Plant and Soil Sciences Department, Oklahoma State University, \\ Stillwater, MN, USA \\ *These authors contributed equally to this study. \\ Corresponding author: S.Q. Bai \\ E-mail: baiturf@yahoo.com.cn
}

Genet. Mol. Res. 11 (2): 1245-1253 (2012)

Received June 15, 2011

Accepted December 20, 2011

Published May 9, 2012

DOI http://dx.doi.org/10.4238/2012.May.9.3

\begin{abstract}
Saccharum spontaneum is a wild sugarcane species that is native to and widely distributed in China. It has been extensively used in sugarcane breeding programs, and is being tested for the development of bioenergy cultivars. In order to provide basic information for the exploitation of this species, we analyzed genetic variation among and within native $S$. spontaneum populations collected from Sichuan, China. Eighty plants from nine native populations were sampled. Twentyone sequence-related amplified polymorphism primer pairs generated 235 clearly scorable bands, of which 185 were polymorphic (78.7\%). Nei's genetic diversity was 0.2801 and Shannon's information index was 0.4155 across the populations. Genetic diversity parameters, $G_{\mathrm{ST}}$ value (0.2088) and $N_{\mathrm{m}}$ value (1.8944), showed that the genetic variation within populations was greater than that among populations. In the
\end{abstract}


cluster analysis, one major grouping was formed by populations from Ya'an and another one by populations from Sichuan basin; a population from Baoxing formed a single cluster. In order to fully comprehend the genetic diversity of cold-tolerant local germplasm in this species, germplasm should be collected from the heterogeneous environments along the northern regions of this species' distribution. The germplasm that we collected should be a valuable resource for Saccharum breeding.

Key words: Saccharum spontaneum; SRAP; Genetic diversity; Diversity index; Genetic structure

\section{INTRODUCTION}

Saccharum spontaneum is the major wild species extensively used in sugarcane genetic improvement and cultivar development worldwide for its resistance to abiotic and biotic stresses (Ming et al., 2006). More recently, S. spontaneum crossed with selected sugarcane clones (S. officinarum or Saccharum hybrids) has been deployed to produce early generation hybrids selected for sugar-fiber energy cane or fiber-only energy cane as a bioenergy crop (Tew and Cobill, 2010). Hybrids are selected for adaptation to more temperate environments and production of higher biomass yields compared to traditional sugarcane cultivars. New germplasm in $S$. spontaneum will provide genetic materials with considerable potential, needed for new bioenergy cultivar development. More specifically those collected from more temperate and humid regions can contribute to desirable genes for cold tolerance and disease resistance.

S. spontaneum is widespread in China within a vast geographic range of northern latitudes $18^{\circ} \sim 33^{\circ}$ and east longitudes $97^{\circ} \sim 122^{\circ}$, covering the provinces of Anhui, Fujian, Guangdong, Guangxi, Guizhou, Hainan, Henan, Hubei, Hunan, Jiangsu, Jiangxi, Shaanxi, Sichuan, Taiwan, Xinjiang, Xizang, Yunnan, and Zhejiang (Chen and Phillips, 2006). An early report indicated that most clones of Chinese $S$. spontaneum from southwest provinces were $2 \mathrm{n}=80$, and some $2 \mathrm{n}=64$, in addition to rare ones being $2 \mathrm{n}=68$ or 116 (Chen et al., 1981). Chinese native $S$. spontaneum possesses a large variation in tillering ability, photosynthetic efficiency and dry matter accumulative ability (Xie et al., 2007). Using random amplified polymorphic DNA (RAPD) markers, Zhang et al. (2010) studied the genetic diversity of local S. spontaneum accessions collected from the Guangxi Zhuangzu Autonomous Region, a southern province in China. Zhang et al. (2006) also reported large phenotypic variation for seven selected quantitative traits of the same germplasm collections from Guangxi. We collected native S. spontaneum germplasm in 2008 from the Sichuan Province representing more northern regions of the species' adaptation. As the regions are humid and more temperate than Guangxi, our collections may contain desirable traits encompassing cold tolerance and disease resistance. However, the genetic diversity of our germplasm collections was unknown.

Sequence-related amplified polymorphism (SRAP) was developed as a reliable molecular marker system based on simple PCRs of genomic DNA (Li and Quiros, 2001). SRAP analyzes DNA polymorphisms with amplifying open reading frames using specifically designed primers. The objective of the current investigation was to analyze genetic variation among natural $S$. spontaneum populations collected from Sichuan based on SRAP. 


\section{MATERIAL AND METHODS}

\section{Plant materials}

Experimental plant materials of native $S$. spontaneum were collected from the main valleys of the Min River, Qingyi River and Tuo River in Sichuan Province, China, in September 2008 (Figure 1). According to the sampling method of collecting different populations by Jing and Lu (2003), each local population was sampled by collecting leaf tissues from 5 to 15 randomly selected individual plants, in situ, on the basis of the population size at a selected location. Ramets of each sampled plant were dug up and transplanted to an observation nursery for morphological characterization experiments (data not shown). Totally, we collected samples and germplasm of nine populations consisting of 80 individuals. Location and habitat conditions of the nine populations are given in Table 1.

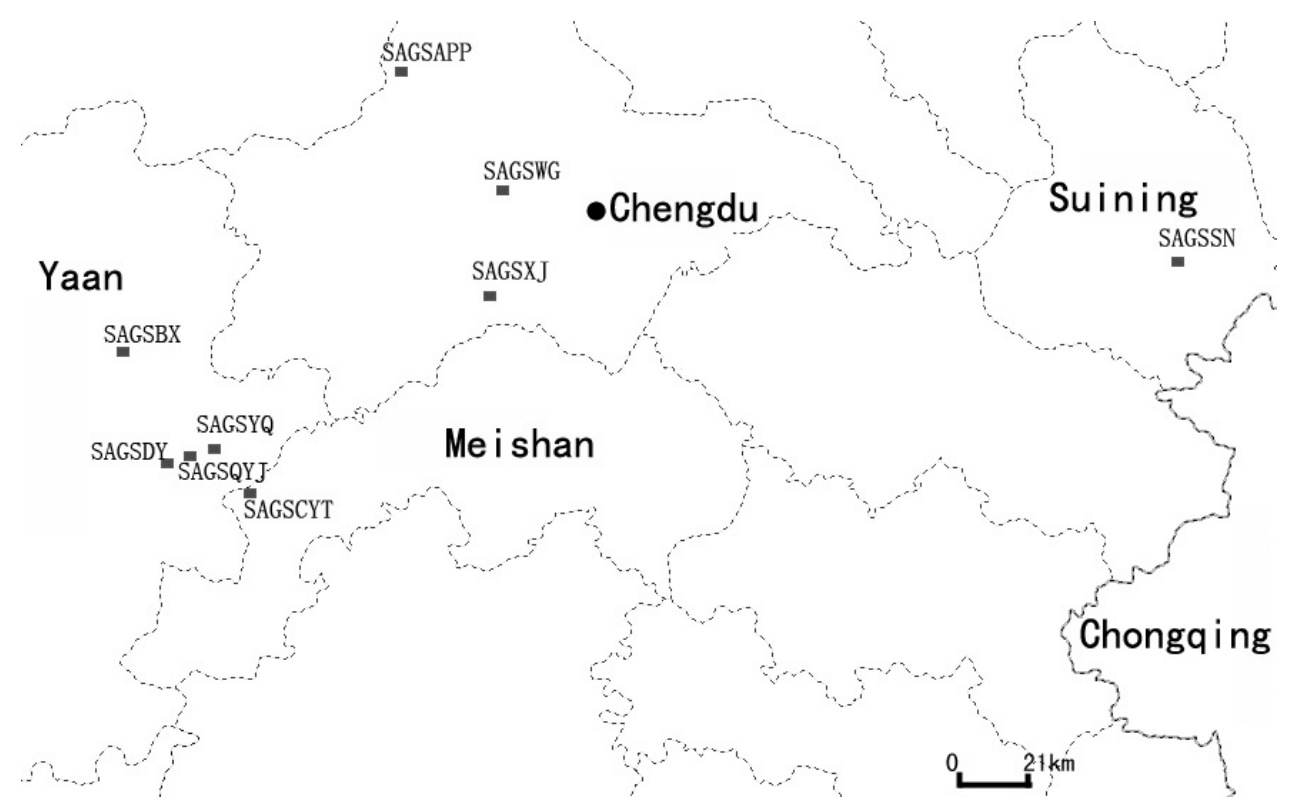

Figure 1. Local map of Sichuan, China, showing sampling locations.

\begin{tabular}{|c|c|c|c|c|c|c|}
\hline Identity & Location & Altitude (m) & Latitude & Longitude & Habitat & Individuals per population \\
\hline $\begin{array}{l}\text { SAGSQYJ } \\
\end{array}$ & Qingyi River, Yaan & 562 & $29^{\circ} 59^{\prime}$ & $103^{\circ} 00^{\prime}$ & Riverside & 15 \\
\hline SAGSDY & Duoyun, Yaan & 593 & $29^{\circ} 59^{\prime}$ & $102^{\circ} 57^{\prime}$ & Roadside & 7 \\
\hline SAGSBX & Baoxing, Yaan & 795 & $30^{\circ} 15^{\prime}$ & $102^{\circ} 49^{\prime}$ & Riverside & 9 \\
\hline SAGSYQ & Yaoqiao, Yaan & 543 & $30^{\circ} 01^{\prime}$ & $103^{\circ} 35^{\prime}$ & Riverside & 5 \\
\hline SAGSCYT & Caoyutan, Yaan & 486 & $29^{\circ} 51^{\prime}$ & $103^{\circ} 14^{\prime}$ & Riverside & 10 \\
\hline SAGSZPP & Zipingpu, Dujiangyan & 737 & $31^{\circ} 01^{\prime}$ & $103^{\circ} 35^{\prime}$ & Riverside & 8 \\
\hline SAGSXJ & Xinjin, Chengdu & 532 & $30^{\circ} 23^{\prime}$ & $103^{\circ} 48^{\prime}$ & Slope shrub & 6 \\
\hline SAGSWJ & Wenjiang, Chengdu & 525 & $30^{\circ} 40^{\prime}$ & $103^{\circ} 46^{\prime}$ & Riverside & 10 \\
\hline SAGSSN & Dongchan, Suining & 310 & $30^{\circ} 32^{\prime}$ & $105^{\circ} 32^{\prime}$ & Slope shrub & 10 \\
\hline
\end{tabular}




\section{DNA isolation}

Fresh and young leaves of $S$. spontaneum were hand collected from individual selected plants as individual samples, and each sample was dried separately using self-indicating silica gel. These leaf tissues were taken back to the laboratory and stored in a freezer at $-80^{\circ} \mathrm{C}$ for use. Genomic DNA was isolated from the collected leaf tissues using the modified CTAB method of Doyle (1991). Integrity and quality of DNA samples were evaluated by electrophoresis on $0.8 \%$ agarose gels containing $0.5 \mu \mathrm{g} / \mathrm{mL}$ ethidium bromide and quantified in a UV spectrophotometer. Qualified DNA samples were stored in a refrigerator at $4{ }^{\circ} \mathrm{C}$ for PCR.

\section{SRAP-PCR procedure}

The volume per PCR was $20 \mu \mathrm{L}$. The reaction chemical components included $4 \mu \mathrm{L}$ $10 \mathrm{ng} / \mu \mathrm{L}$ DNA, $2 \mu \mathrm{L}$ 10X PCR buffer, $2 \mu \mathrm{L} 25 \mathrm{mM} \mathrm{Mg}^{2+}, 2.4 \mu \mathrm{L} 2.5 \mathrm{mM}$ dNTPs, $0.2 \mu \mathrm{L} 5$ $\mathrm{U} / \mu \mathrm{L}$ Taq DNA polymerase, $1 \mu \mathrm{L} 10 \mathrm{mM}$ upstream primer, $1 \mu \mathrm{L} 10 \mathrm{mM}$ downstream primer, and $7.6 \mu \mathrm{L}$ of sterile water. One hundred and twenty primer pairs of 10 upstream primers and 12 downstream primers published by Li and Quiros (2001) were screened for effective amplification, clear bands, high polymorphisms and reliability. The primers were synthesized by Shanghai Biochemical Engineering Technology (Shanghai, China). The SRAP markers were amplified using the following thermal cycle parameters: $5 \mathrm{~min}$ at $94^{\circ} \mathrm{C} ; 5$ cycles of $94^{\circ} \mathrm{C}$ for $1 \mathrm{~min}, 35^{\circ} \mathrm{C}$ for $1 \mathrm{~min}$, and $72^{\circ} \mathrm{C}$ for $2 \mathrm{~min} ; 35$ cycles of $94^{\circ} \mathrm{C}$ for $1 \mathrm{~min}, 50^{\circ} \mathrm{C}$ for $1 \mathrm{~min}$, and $72^{\circ} \mathrm{C}$ for $1 \mathrm{~min}$; extension of $5 \mathrm{~min}$ at $72^{\circ} \mathrm{C}$; and a final storage at $4^{\circ} \mathrm{C}$. The PCR products were separated and visualized using $2 \%$ agarose gel electrophoresis.

\section{Data analysis}

Clearly amplified PCR bands were visually scored as " 1 " for presence of one band or "0" for absence of any band in a specific sample. The percentage of polymorphic bands (PPB), Shannon's information index $(I)$, Nei's gene diversity $(h)$, genetic diversity within populations $\left(H_{\mathrm{S}}\right)$, total genetic diversity $\left(H_{\mathrm{T}}\right)$, genetic differentiation coefficient $\left(G_{\mathrm{ST}}\right)$, gene flow estimates $\left(N_{\mathrm{m}}\right)$, and the Nei's genetic distance were calculated using POPGENE (Yeh and Boyle, 1999). Cluster analysis (UPGMA dendrogram) of the different populations was performed with the SHAN module in the NTSYS software using Nei's genetic distances (Rohlf, 2000).

\section{RESULTS}

\section{SRAP primer selection and analysis}

Twenty-one SRAP primer combinations (PCs) were selected from 120 PCs in a screening test (data not shown). The selected SRAP PCs were used in the PCR amplifications of 80 S. spontaneum DNA samples of 9 populations. PCR bands were scored if they were clearly readable. The PCs yielded a total of 235 scored bands, of which 185 were polymorphic. The number of amplified and scored bands for each primer pair varied from 4 to 13, with an average of 8.81 (Table 2). 
Table 2. Primer sequences used in SRAP analyses of Saccharum spontaneum and their amplification parameters.

\begin{tabular}{lccc}
\hline Primer combinations* & Total bands & Polymorphic bands & Percent polymorphic bands \\
\hline em1+me8 & 10 & 8 & 80.00 \\
em1+me9 & 9 & 8 & 88.89 \\
em2+me9 & 8 & 4 & 50.00 \\
em3+me2 & 11 & 9 & 81.82 \\
em3+me3 & 11 & 8 & 72.73 \\
em3+me4 & 12 & 12 & 100.00 \\
em5+me3 & 9 & 7 & 77.78 \\
em3+me6 & 11 & 10 & 90.91 \\
em3+me7 & 12 & 11 & 91.67 \\
em5+me4 & 13 & 12 & 92.31 \\
em5+me9 & 15 & 13 & 86.67 \\
em7+me5 & 11 & 9 & 81.82 \\
em8+me5 & 11 & 6 & 54.55 \\
em8+me6 & 9 & 6 & 66.67 \\
em8+me8 & 9 & 4 & 44.44 \\
em9+me2 & 11 & 7 & 63.64 \\
em9+me3 & 11 & 9 & 81.82 \\
em9+me5 & 12 & 10 & 83.33 \\
em9+me7 & 14 & 11 & 78.57 \\
em9+me9 & 13 & 11 & 84.62 \\
em10+me3 & 13 & 10 & 76.92 \\
Mean & 11.19 & 8.81 & 77.45 \\
Total & 235 & 185 & 78.72 \\
- 35 &
\end{tabular}

*Primer sequence information published by Li and Quiros (2001).

\section{Genetic diversity and population relationship}

The PPB among individuals across all populations was $78.72 \%$. PPB within populations showed a large range. For example, population SAGSQYJ had the highest value of PPB at $70.21 \%$, followed by $62.13 \%$ for SAGSBX and SAGSCYT. The lowest PPB value was $52.77 \%$ for population SAGSYQ. The resultant mean PPB within populations was $59.43 \%$ (Table 3).

Table 3. Genetic diversity of 9 populations of Saccharum spontaneum.

\begin{tabular}{lcccccc}
\hline Population & $\begin{array}{c}\text { No. of polymorphic } \\
\text { bands }\end{array}$ & $\begin{array}{c}\text { Percent } \\
\text { polymorphic bands }\end{array}$ & $\begin{array}{c}\text { Observed number } \\
\text { of alleles }\end{array}$ & $\begin{array}{c}\text { Effective number } \\
\text { of alleles }\end{array}$ & $\begin{array}{c}\text { Nei's gene } \\
\text { diversity }(h)\end{array}$ & $\begin{array}{c}\text { Shannon's } \\
\text { information index }(I)\end{array}$ \\
\hline SAGSQYJ & 165 & 70.21 & 1.6936 & 1.3980 & 0.2347 & 0.3539 \\
SAGSDY & 134 & 57.02 & 1.5660 & 1.3827 & 0.2206 & 0.3249 \\
SAGSBX & 146 & 62.13 & 1.6170 & 1.4102 & 0.2347 & 0.3466 \\
SAGSYQ & 124 & 52.77 & 1.5277 & 1.3812 & 0.2158 & 0.3147 \\
SAGSCYT & 146 & 62.13 & 1.6170 & 1.3631 & 0.2150 & 0.3236 \\
SAGSZPP & 130 & 55.32 & 1.5532 & 1.3532 & 0.2056 & 0.3056 \\
SAGSXJ & 126 & 53.62 & 1.5277 & 1.3523 & 0.2035 & 0.3007 \\
SAGSWJ & 145 & 61.70 & 1.6170 & 1.3977 & 0.2309 & 0.3425 \\
SAGSSN & 141 & 60.00 & 1.6000 & 1.4102 & 0.2334 & 0.3430 \\
Mean & 139 & 59.43 & 1.5910 & 1.3832 & 0.2216 & 0.3284 \\
Species & 235 & 78.72 & 1.7872 & 1.4854 & 0.2801 & 0.4155 \\
SD & 13 & 5.44 & 0.0533 & 0.0228 & 0.0124 & 0.0191 \\
\hline
\end{tabular}

The $H_{\mathrm{T}}$ of the $S$. spontaneum populations was 0.2801 by the Nei's gene diversity $(h)$. The Nei's gene diversity values of the 9 populations ranged from 0.2035 to 0.2347 , with an average of 0.2216 . The $H_{\mathrm{T}}$ by Shannon's index $(I)$ was estimated to be 0.4155 higher than Nei's 
index, and Shannon's index of the 9 populations varied between 0.3007 and 0.3539 , with an average of 0.3284. However, Shannon's index and Nei's index were parallel if compared. Of the nine populations, SAGSQYJ had the highest gene diversity $(h=0.2347, I=0.3539)$ and SAGSXJ had the lowest $(h=0.2035, I=0.3007)$ (Table 3 ).

Given the assumption of genetic equilibrium, $H_{\mathrm{S}}$ within the nine $S$. spontaneum populations was 0.2216 , while the $H_{\mathrm{T}}$ among the populations was 0.2801 . The $G_{\mathrm{ST}}$ and $N_{\mathrm{m}}$ were 0.2088 and 1.8944, respectively. Genetic similarity coefficients among the $9 S$. spontaneum populations are presented in Table 4 . Pairwise genetic similarity coefficients between populations varied from 0.91 (SAGSZPP and SAGSBX, SAGSCYT and SAGSBX) to 0.96 (SAGSWJ and SAGSSN, SAGSQYJ and SAGSYQ, SAGSXJ and SAGSWJ).

\begin{tabular}{|c|c|c|c|c|c|c|c|c|}
\hline Population (No.) & 2 & 3 & 4 & 5 & 6 & 7 & 8 & 9 \\
\hline SAGSQYJ (1) & 0.94 & 0.93 & 0.96 & 0.95 & 0.94 & 0.94 & 0.94 & 0.94 \\
\hline SAGSDY (2) & & 0.92 & 0.95 & 0.94 & 0.93 & 0.93 & 0.93 & 0.92 \\
\hline SAGSBX (3) & & & 0.92 & 0.91 & 0.91 & 0.92 & 0.94 & 0.92 \\
\hline SAGSYQ (4) & & & & 0.94 & 0.92 & 0.93 & 0.92 & 0.92 \\
\hline SAGSCYT (5) & & & & & 0.93 & 0.92 & 0.93 & 0.92 \\
\hline SAGSZPP (6) & & & & & & 0.95 & 0.94 & 0.95 \\
\hline SAGSXJ (7) & & & & & & & 0.96 & 0.94 \\
\hline SAGSWJ (8) & & & & & & & & 0.96 \\
\hline SAGSSN (9) & & & & & & & & \\
\hline
\end{tabular}

Cluster analysis generated a UPGMA dendrogram given in Figure 2. Three major clusters were identified at the similarity level of 0.93 . The first cluster was composed of SAGSQYJ, SAGSYQ, SAGSDY, and SAGSCYT. The second cluster contained SAGSZPP, SAGSXJ, SAGSWJ, and SAGSSN. Population SAGSBX formed one distinct cluster.

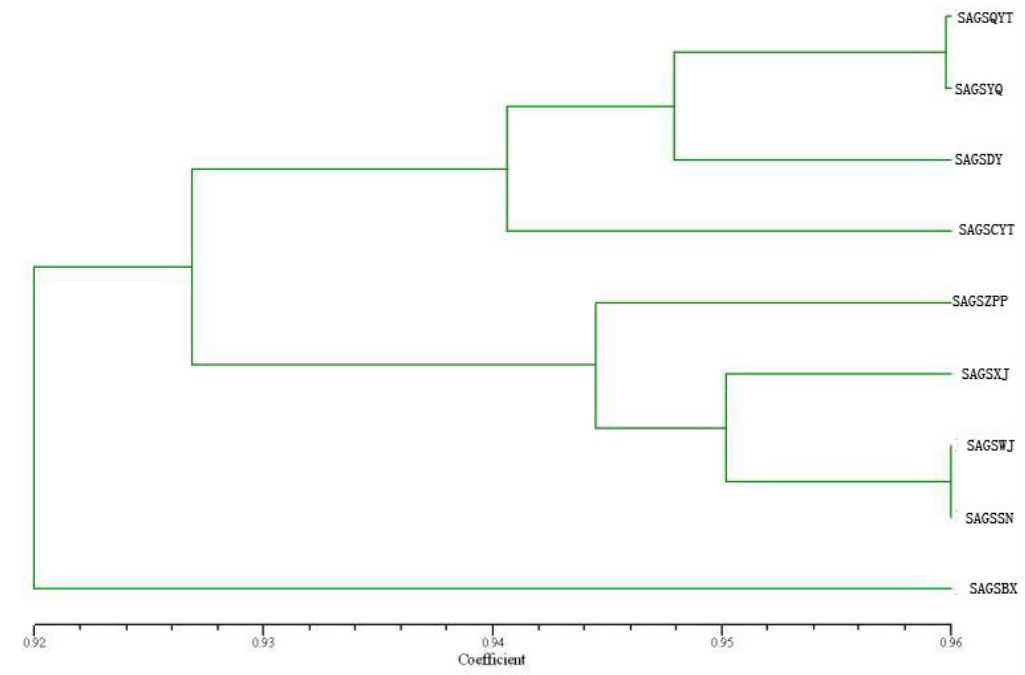

Figure 2. UPGMA dendrogram for 9 populations of Saccharum spontaneum based on Nei's genetic distance. 


\section{DISCUSSION}

Of all Saccharum species, S. spontaneum has very wide geographic distribution from tropics to subtropics, resulting in the most diverse germplasm, which has been substantially used in sugarcane breeding programs (Ming et al., 2006), and are being deployed in the development of bioenergy cultivars (Tew and Cobill, 2010). Genetically diverse germplasm of $S$. spontaneum can effectively contribute to disease resistance, cold tolerance, insect resistance, and tillering potential to new breeding products. Pan et al. (2004) used 157 polymorphic RAPD markers in an assessment of the genetic diversity of an S. spontaneum collection of 33 accessions from India, Indonesia, Australia, Taiwan, Philippines, and the USA, maintained at the USDA-ARS Southern Regional Research Center, Sugarcane Research Unit, in Houma, LA, USA. They reported pairwise genetic homology coefficients in the accessions ranging from 0.65 to 0.89 . Mary et al. (2006) used 410 polymorphic DNA markers in an analysis of the genetic diversity of $40 \mathrm{~S}$. spontaneum accessions collected from four different geographic regions in India. Their results indicated that pairwise genetic similarity coefficients between the native accessions varied from 0.40 to 0.70 , and that genetic diversity was associated with geographic origin. Using 84 polymorphic RAPD markers, Zhang et al. (2010) reported the genetic diversity of 89 S. spontaneum accessions collected from five different ecological regions of Guangxi, China. They found that the local germplasm was genetically diverse with pairwise similarity coefficients being from 0.26 to 0.91 . In our current study, SRAP PCR amplification of nine S. spontaneum wild populations generated 185 polymorphic markers. The results indicated that the PPB of the nine populations was $78.82 \%$. The SRAP results in this study were comparable to those of the RAPD study by Yang et al. (1998) and Zhang et al. (2010), which were 72.5 and $74.84 \%$, respectively.

However, we assessed the genetic diversity of native S. spontaneum germplasm using populations instead of individual clones used by the above cited investigations. Therefore, we found that the Nei's genetic diversity parameter at the species level was 0.2801 higher than that (0.2216) at the population levels. According to the findings of Nybom and Bartish (2000), Nei's genetic diversity of monocotyledons is in an average of 0.190 . Total Nei's genetic diversity and genetic diversity within populations in our study were both higher than the average value of monocotyledons, and therefore, we can conclude that the native $S$. spontaneum collected in Sichuan, China, was genetically diverse.

Hamrick and Godt (1989) pointed out that the majority (ca. 90\%) of genetic variation of outcrossing wind-pollinated species involving 165 genera resided within populations, while the remaining small portion of genetic diversity resided between populations. We found that the genetic variation within populations $(0.7912)$ is much greater than that between populations (0.2088), indicating that the local $S$. spontaneum germplasm was largely outcrossing in nature. Wright (1951) pointed out that gene flow would be able to resist the effect of genetic drift within populations and prevent the differentiation of populations as the value of $N_{\mathrm{m}}>1$. The genetic drift can lead to genetic differentiation among populations with $N_{\mathrm{m}}<1$. The $N_{\mathrm{m}}$ value in this study was 1.8944 , indicating that there was no significant genetic differentiation between the 9 populations, substantiating the notion that $S$. spontaneum plants had crosspollinating reproduction.

It is not difficult to find in the dendrogram (Figure 2) that the clusters were closely related to their geographic origins and surrounding geographic environments. The populations 
collected along the Qingyi River in Ya'an formed one major cluster except one population from Baoxing. Although the location in Baoxing is close to the others in Ya'an, the population SAGSBX was not clustered with the remaining populations from Ya'an. Baoxing is located in the upper stream of the Qingyi River and its relatively colder climate due to its high altitude may have an impact on genetic differentiation. The second major cluster consisted of populations collected from Dujiangyan, Xinjin, Wenjiang, and Suining. The four locations belong to the west-central part of Sichuan basin, i.e., similar climates. Therefore, it appears that geographic distance and environmental factors including local climates interplay in the formation of the genetic structure and geographic patterns of the native S. spontaneum populations. The results clearly indicated that fuller sampling of the genetic diversity of cold-tolerant local germplasm in the species requires comprehensive germplasm collection in heterogeneous environments along the northern regions of the species distribution. The germplasm should be a valuable source in Saccharum breeding.

\section{ACKNOWLEDGMENTS}

Research supported by the National High-Tech R\&D Program of China (863 Program, \#2012AA101801-01), the Molecular Breeding and New Germplasm Development for Energy Grass on Marginal Land (973 Program, \#2012CB215300) and the Sichuan Academy of Grassland Sciences, Sichuan Province, China. The Department of Grassland Science, Sichuan Agricultural University provided laboratory facilities to perform the experiments.

\section{REFERENCES}

Chen CL, Li LF and Wu SZ (1981). Chromosome number distribution of Saccharum spontaneum in the southwest region of China. Intl. Sugar J. 83: 264-267.

Chen SL and Phillips SM (2006). Saccharum Linnaeus. Flora China 22: 576-581.

Doyle JJ (1991). DNA Protocols for Plants-CTAB Total DNA Isolation. In: Molecular Techniques in Taxonomy (Hewitt GM and Johnston A, eds.). Spring-Verlag, Berlin, 283-293.

Hamrick JL and Godt MJ (1989). Allozyme Diversity in Plant Species. Sinauer Associates, Sunderland.

Jing Y and Lu BR (2003). Sampling strategy for genetic diversity. Chin. Biodivers. 11: 155-161.

Li G and Quiros CF (2001). Sequence-related amplified polymorphism (SRAP), a new marker system based on a simple PCR reaction: its application to mapping and gene tagging in Brassica. Theor. Appl. Genet. 103: 455-461.

Mary S, Nair NV, Chaturvedi PK and Selvi A (2006). Analysis of genetic diversity among Saccharum spontaneum L. from four geographic regions in India, using molecular markers. Genet. Resour. Crop Evol. 53: 1221-1231.

Ming R, Moore PH, Wu KK, D’Hont A, et al. (2006). Sugarcane improvement through breeding and biotechnology. Plant Breed. Rev. 27: 15-118.

Nybom H and Bartish IV (2000). Effects of life history traits and sampling strategies on genetic diversity estimates obtained with RAPD markers in plants. Plant Ecol. Evol. Syst. 3: 93-114.

Pan YB, Burner DM, Legendre BL, Grisham MP, et al. (2004). An assessment of the genetic diversity within a collection of Saccharum spontaneum L. with RAPD-PCR. Genet. Resour. Crop Evol. 51: 895-903.

Rohlf FJ (2000). NTSYS-pc Numerical Taxonomy and Multivariate Analysis System, Version 2.1. User Guide. Exeter Software, Setauket.

Tew TL and Cobill RM (2010). Genetic Improvement of Sugarcane (Saccharum spp.) as an Energy Crop. In: Genetic Improvement of Bioenergy Crops (Vermerris W, ed.). Springer, New York.

Wright S (1951). The genetical structure of populations. Genetics 15: 323-354.

Xie GH, Guo XQ and Wang X (2007). An overview and perspectives of energy crop resources. Resour. Sci. 29: 74-80.

Yang QH, Li FS and Xiao FH (1998). Analysis of RAPD fingerprinting on Saccharum spontaneum L. J. Yunnan Agri. Univ. 13: 347-351.

Yeh FC and Boyle TJ (1999). Popgene version 1.31. Microsoft Window-Based Freeware for Population Analysis. 
University of Alberta and Centre for International Forestry Research, Edmonton.

Zhang GM, Yang RZ, Liu HB and Fang WK (2006). Principal component analysis for 7 quantitative traits and cluster analysis based on 7 quantitative traits of Saccharum spontaneum L. Southwest China. J. Agric. Sci. 19: 1127-1131.

Zhang GM, Li YR, He WZ, He H, et al. (2010). Analysis of the genetic diversity in Saccharum spontaneum L. accessions from Guangxi province of China with RAPD-PCR. Sugar Tech 12: 3118. 